\title{
Effects of a Programmed Corrective Training on Postural Disorders in Lumbar and Thoracic Region
}

\author{
Zoran Bogdanović ${ }^{\text {, FahrudinMavrić }}{ }^{\text {, Adem Mavrić }}{ }^{2}$ \\ ${ }^{1}$ State University of Novi Pazar, Department for Biomedical sciences, Novi Pazar, Serbia, \\ ${ }^{2} \mathrm{PhD}$ student at the Faculty of Sport and Physical Education, University of Niš, Serbia
}

\begin{abstract}
The purpose of this research is to understand the influence of applied corrective gymnastic on the disturbances in the sagittal plane (kyphosis and lordosis), in a period of one school year, in population of primary school age in classes of regular physical education. The research was conducted in Serbia, on the territory of Novi Pazar, participants were age $12 \pm 6$ months, height 147,25 cm (SD $\pm 6,71)$ and weight of 38.90 $\mathrm{kg}(\mathrm{SD} \pm 7.37)$. Primary school students were examined (194 males and 128 females).

Using Spinal Mouse, kifotic and lordotic bad posture was assessed, and the variables used for the assessment of morphological space were: body height, body weight, chest circumference, shoulder width, pelvis width, abdominal skinfold and back skinfold. Descriptive statistics were used for the purpose of this study, and central and dispersion parameters of morphological and postural variables were calculated. Using one-factor analysis of variance (ANOVA) of repeated measurements, the effects of programmed corrective exercises were determined. The results showed that in investigated population the improvement of the position of the spinal column has occurred. Significant influence of period of practice was found in both cases. In KIF Vilksov lambda $=0.11, F=508.99, p<0.0005$, multivariate partial eta squared $=0.84$. In LORD Vilksov lambda $f=0.15, F=$ 476.80, $p<0.0005$, multivariate partial eta squared $=0.88$. Based on the given Eta Squared values, it is identified that the impact of the practice on the treated postural disorders (KIF and LORD) is very large.
\end{abstract}

Keywords: Corrective gymnastics, kyphosis, lordosis, primary school students

\section{INTRODUCTION}

Bad posture is not only a disorder, one particular deformation, has more deformations, with common feature that with the active muscle tightening, they disappear. Bad posture is characterized by the weakness of the whole body, especially the joint-muscular apparatus. In this situation the most expressed is static failure of the spinal column, which is caused by weakness of other parts of the locomotor system (Bogdanovic, 2005).

The rapid growth from childhood to adolescence occurs in ages 9-12 years and can cause enormous changes in position, shape and size and has an effect on muscle strength and flexibility, all of which can affect their postural status. (Karlin, 1986; Wojtys, 1987). The increase in body mass in children may lead to increased difficulty in maintaining static equilibrium. (Shumway-Cook A. Woollacott MH., 2001). The development phase of postural responses may affect a child's ability to maintain a relaxed standing position. Motor and sensory systems involved in postural stability are going through a transition period of 4-6 years up to adult maturity of 7-10 years. (Forssberg, Nashner, 1982; Schumway-Cook, Woollacott, 1985; Woollacott, et all. 1988; Woollacott, et all. 1988).

Spinal deformities in adolescents and school children are in the growth primarily because of external factors such as: debt compulsive condition, inadequate furniture, reduced physical activity and heavy school bags that affect bad posture. In school children especially adolescents, in the last 15 years the percentage of deformities has increased, in females from $0.93 \%$ to $1.37 \%$, in males from $0.25 \%$ to $2.25 \%$ with idiopathic scoliosis, except, there is no difference in the prevalence in patients of rural and industrial areas(Bogdanovic, 2008).

Spine deformities are observed in the structural and functional disorders of cardiorespiratory and locomotor system due to narrow and asymmetric chest. These changes lead to reduced physical activity, depression, back pain, fatigue and reduced work ability. The first symptoms are manifested even in school children, emphasizing in adolescents, and reducing the working capacity of adults. 
They are connected by unknown factors as in idiopathic scoliosis and with established external factors: reduced physical activity, increased compulsive conditions and load of the spine.

To remediate disorders of the spinal column it is required to apply adequate physical exercises that will strengthen the weakened muscles and bring back the spinal column to normal condition. All this is valid only if the disorders are registered in time, while the spinal column is in working condition. If the disorder progresses to deformity, then the recovery process is difficult and lasts longer. As physical inactivity in the studied population is presented in a high percentage, corrective gymnastics and sport in several studies are referred as a preventive measures of disorders of the spinal column. (Woollacott, 1986; Woollacott, et al, 1986; Dondur, et al. 2011; Purenovic, 2007).

\subsection{The Main Problem and the Subject of the Study}

The problem of this research are postural disorders of the spinal column in the sagittal plane kyphotic and lordotic bad posture in early school age, and the implementation of planned methodology of working with a goal to remove existing disorders by exercising in a regular physical education classes. The research study represented the influence of specially programmed education that are specified with a complex of exercises on students of primary school, where the conducted measurements showed the presence of kyphotic and lordotic bad posture(Bogdanovic, 2010).

\section{METHODS}

The study of longitudinal character, was conducted in Serbia on the territory of Novi Pazar. The sample of respondents consisted of 322 primary school students, 194 men and 128 women, with age $12 \pm 6$ months and an average height of $147,25 \mathrm{~cm}(\mathrm{SD} \pm 6,71)$ and average weight of $38.90 \mathrm{~kg}(\mathrm{SD} \pm$ 7.37).

Using two variables that estimate disorders of the spinal column in the saggital plane - kyphotic (KIF) and lordotic (LORD) bad body posture, postural assessment was performed. To estimate morphological space, two variables were used: body height (AVIS), body weight (ATEZ), circumference of the thorax (AOGK), shoulder width (ASIR), the width of the pelvis (ASIK), abdominal skin folds (AKNT) and skin folds on the back (AKNL).

\subsection{Instruments and Procedures}

A non-invasive method of measurement called Spinal mouse was used to estimate kyphotic and lordotic bad body posture. (Idiag, Fehraltdorf, Švicarska, www.idiag.ch). Spinal Mouse is a computer device that determines the postural status (thoracic and lumbar part of the spine, pelvic tilt, sectional angles and the length of the sectional parts) and mobility (range of motion: flexion, extension). Spinal Mouse offers measurement with high precision and objectivity, while from the point of participants, it represents a non-invasive method and it does not require exposure to radioactivity. Its validity and reliability have been confirmed in studies of Mannion, et al. (2004); Guermazi et al. (2006), Post, R.B. \& Leferink, (2004).

For the purposes of this study the only data deviation of the spinal column in the thoracic and lumbar region was used. Measurement of postural status of participants was conducted in a standing position, and the parameters were recorded graphically and numerically. With the aim of classifying disorders posture by category, we used the values determined by the Cobb. Normal values of kyphosis are 20$35^{\circ}$, while normal values of lordosis are $15-30^{\circ}$. The collected data were analyzed using statistical data analysis, SPSS 17th. To obtain the values of anthropometric parameters, International Biological Program (IBP) was used. Instruments were standard designing and calibrated before the measurement.

\subsection{Organization of Experimental Program and Time of Implementation}

The program was manifested through a special way of work in physical education classes, in a period of 9 months. The beginning of experimental program is directly related to the beginning of the school year when initial measurement of all respondents was done. After forming the experimental group, the beginning of the experiment has started.

Respondents with the present disorders have begun with the implementation of the planned program. They had the task to do the complete set of corrective exercises three times a week in regular physical education classes, planned in advance. This kind of a work was performed in continuity for a whole semester (4 months) until the winter break, which lasted 14 days. In the last week, before the end of 
the semester, a control measurement was done. At the beginning of the second semester the corrective work had continued until the end of the school year (5 months), and one week before the end of the school year the final measurement was done.

\subsection{Statistical Analysis}

Descriptive statistics were used for the purpose of this study, where central and dispersion parameters of morphological and postural variables were calculated. Arithmetic mean and standard deviation were calculated for each variable. To determine the effects of programmed corrective exercises at control measurement and final measurement in relation to the initial situation, we applied factor analysis of variance (ANOVA) of repeated measurements. SPSS Statistical Package for Social Sciences (v17.0, SPSS Inc., Chicago, IL) was used for statistical analysis.

\section{RESULTS}

Table1. Descriptive Statistics on the First, Second and Third Measurement

\begin{tabular}{|l|l|l|l|l|}
\hline Varijable & $\mathrm{N}$ & Initial measurement & Control measurements & Final measurement \\
\hline AVIS $(\mathrm{cm})$ & 322 & $147,25 \pm 6,71$ & $148,3118 \pm 6.93$ & $150,40 \pm 6,93$ \\
\hline ATEZ $(\mathrm{kg})$ & 322 & $38,90 \pm 7,37$ & $39,60 \pm 7.00$ & $41,64 \pm 7,67$ \\
\hline AOGK $(\mathrm{cm})$ & 322 & $71,51 \pm 6,18$ & $72,05 \pm 6,12$ & $73,54 \pm 6,28$ \\
\hline ASIR $(\mathrm{cm})$ & 322 & $30,21 \pm 1,59$ & $30,33 \pm 1,58$ & $30,95 \pm 1,67$ \\
\hline ASIK $(\mathrm{cm})$ & 322 & $21.34 \pm 1.54$ & $21.70 \pm 1.48$ & $22.56 \pm 1.65$ \\
\hline AKNT $(\mathrm{mm})$ & 322 & $11,44 \pm 7,13$ & $11,93 \pm 7,44$ & $13,01 \pm 8,33$ \\
\hline AKNL $(\mathrm{mm})$ & 322 & $9,51 \pm 5,85$ & $9,61 \pm 5,91$ & $10,16 \pm 6,61$ \\
\hline KIF $\left(^{0}\right)$ & 194 & $38,61 \pm 0,70$ & $35,75 \pm 0,64$ & $32,31 \pm 0,34$ \\
\hline LORD $\left(^{0}\right)$ & 128 & $33,39 \pm 0,60$ & $30,70 \pm 0,51$ & $26,15 \pm 0,37$ \\
\hline
\end{tabular}

Results are presented as $A S \pm S D, N=$ number of respondents

Legend: AVIS - body height, ATEZ - body weight, AOGK - circumference of the thorax, ASIR - shoulder width, ASIK - the width of the pelvis, AKNT - abdominal skin folds and AKNL - skin folds on the back.

Table1. shows the results of statistical indicators (mean, standard deviation, $\mathrm{N}$ ) in three measurements for 9 variables. In variable KIF and in variable LORD were recorded the lowest results in final measurement in regards to the initial condition and control measurement, which therefore indicates the efficiency of the applied corrective program. Longitudinal dimensionality of the skeleton that we have defined using variables (AVIS) and body weight of respondents (ATEZ), show a tendency of constant increase, as it was expected. We can conclude that in this age of the primary school students there are noticeable periods that define growth in length, not only of the extremities, but also of the spinal column and pelvic girdle. The mean circumference of the thorax also shows a tendency of constant increase, as expected, and it is conditioned by the development of the skeletal system, muscular apparatus and subcutaneous adipose tissue. The width of the shoulders and hips, as a parameter of transversal dimensionality of the skeleton, indicates also the continuous increase in value, that confirms the ascertainment that the skeletal apparatus harmoniously develops in length and width. It is expected that the mean values that define biacromial range are significantly higher than the mean values of bilicristal range, in all three measurements. Ballast of fat deposits, based on indicators of two variables (AKNT, AKNL), indicates that the abdominal skin folds in comparison to back skin folds had a much more pronounced improvement from the time of initial measurement to the final measurements.

What is concerning, and in direct relation with the longitudinal and transversal dimensionality of the skeleton, it is illogical that the value of the subcutaneous adipose tissue at the time of the dynamic growth of skeletal system is increasing, causing elongation of striated (skeletal) muscle. Our findings show the condition is caused by inappropriate and insufficient quality of nutrition, as well as with reduced physical activity and movement in general.

The last two variables define the space of postural disorders and possible physical deformities. Kyphosis and lordosis represent disorders of the spinal column expressed in the sagittal plane, with localized partial curve whose convexity is going backwards in the chest (thoracic) region, and forward in the lumbar region of the spinal column.

Calculated mean values indicate the fact that the period between initial and final measurement is a period where expressed improvement of corrective posture and position of the spinal column in a sagittal plane were shown. 
The obtained values of central parameters show that there was a continuous increase in value during the experimental period in the space of longitudinal dimensionality of the skeleton. We can also see signs of enlargement in other morphological variables. Transversal dimensionality of skeleton, defined by variables ASIR and ASIK, has increased values in relation to the initial state. But, it must be emphasized that the rate of bone growth in width (transversal dimensionality), is slower than the growth of bones in length (longitudinal dimensionality).

The obtained values of central and dispersion parameters of a given variables (KIF LOR) confirm the correction of kyphotic and lordotic bad posture. At the time of initial measuring, the average value in the variable KIF was $38.61 \pm 0,70$, while the value of the variable LOR was $33.39 \pm 0.60$. The results obtained at the time of control measurements $(\mathrm{KIF}=35.75 \pm 0.64,30.70 \pm \mathrm{LOR}=0.51)$, especially at the time of final measurement $(\mathrm{KIF}=32.31 \pm 0.34,26.15 \mathrm{LOR}= \pm 0.37)$ confirm the fact that there were evident improvement of postural status among the tested population.

Table2. Multivariate Tests of a programmed corrective exercises and kifotic bad posture

\begin{tabular}{|l|l|l|l|l|l|l|l|}
\hline Effect & & Value & $\mathrm{F}$ & $\begin{array}{l}\text { Hypothesis } \\
\text { df }\end{array}$ & Error df & Sig.* & Partial Eta Squared \\
\hline \multirow{3}{*}{ Kyphosis } & Pillai's Trace & 0,84 & 508,99 & 2,000 & 185,000 & 0,00 & 0,84 \\
\cline { 2 - 8 } & Wilks' Lambda & 0,15 & 508,99 & 2,000 & 185,000 & 0,00 & 0,84 \\
\cline { 2 - 8 } & Hotelling's Trace & 5,50 & 508,99 & 2,000 & 185,000 & 0,00 & 0,84 \\
\cline { 2 - 8 } & Roy's Largest Root & 5,50 & 508,99 & 2,000 & 185,000 & 0,00 & 0,84 \\
\hline
\end{tabular}

* Significantly Different at $P \leq 0.05$.

Table3. Multivariate Tests of a programmed corrective exercises and lordotic bad posture

\begin{tabular}{|c|c|c|c|c|c|c|c|}
\hline Effect & & Value & F & Hypothesis df & Error df & Sig.* & Partial Eta Squared \\
\hline \multirow{3}{*}{ lordosis } & Pillai's Trace & 0,88 & 476,80 & 2,00 & 125,00 & 0,00 & 0,88 \\
\cline { 2 - 8 } & Wilks' Lambda & 0,11 & 476,80 & 2,00 & 125,00 & 0,00 & 0,88 \\
\cline { 2 - 8 } & Hotelling's Trace & 7,62 & 476,80 & 2,00 & 125,00 & 0,00 & 0,88 \\
\cline { 2 - 8 } & Roy's Largest Root & 7,62 & 476,80 & 2,00 & 125,00 & 0,00 & 0,88 \\
\hline
\end{tabular}

* Significantly different at $p \leq 0.05$.

In regular physical education classes, the results of a programmed corrective exercises in kyphotic and lordotic bad posture were compared using one-factor analysis of variance of repeated measurements. Their mean values and standard deviations are given in Table 1.

A significant influence of period of practice in both disorders are given in Table 2. In kyphotic bad posture Wikls lambda $=0.11, \mathrm{~F}=508.99, \mathrm{p}<0.0005$, multivariate partial eta squared $=0.84$. In lordotic bad posture Wilks lambda $\mathrm{f}=0.15, \mathrm{~F}=476.80, \mathrm{p}<0.0005$, multivariate partial eta squared $=$ 0.88 .

Since Wilks' Lambda in table 2 is 0.15 , while in Table 3 . it is $00: 11$ with probability 0.00 , which means that $\mathrm{p}<0.0005$, it should be concluded that the groups of mean values are different, ie. that there is a statistically significant effect of exercise on the kyphotic and lordotic bad body posture. Based on the values of Eta Squared of 0.84 (Tab. 2) and 0.88 (Table 3), in accordance with the guidelines proposed by Cohen (1988), we can say that the impact of exercise on postural treatment disorders (KIF and Lord) is very large.

\section{DisCUSSION}

Research results and other authors point to the positive impact of corrective exercises on postural disorders in the studied population.

Gojkovic G. (2009) in his paper determines the effect of physical education on the morphological characteristics and postural status, in a sample of 111 students 11 years old ( \pm 6 months) during one school year. The author has found that there has been a significant increase in the value of most of the applied variables of morphological status, while in postural status has not been any significant changes in final measurements, compared to the initial measurement.

Protic Gava-B. et al.(2010), in the framework of the project 'Exercises for proper posture' determine the effects of exercise on the status of the spinal column in younger children. Students of both sexes with age $8 \pm 6$ months were continuously and systematically subjected to corrective work for four 
months (September-December) 2008. Statistically significant difference were found between the initial and final assessment (in favor of the final) in status of scapulae and thoracic segments of the spinal column that indicates kifotic poor posture. In other segments of the spinal column statistically significant differences were not found.

Obradovic B. et al. (2009), are dealing with the influence of various kinesiology treatments on body composition and bone mineral content of boys in teen years on a sample of 90 subjects with 10-12 years. First group consisted of 32 football players, second group of 28 swimmers, while the nonathletes group consisted of 30 boys who were not actively involved in sports. Statistically significant differences were established between soccer players and control group in terms of overall amount of body fat and bone density ( $p<.01)$. Between the group of swimmers and the control group were also determined significant differences in the total amount of body mass $(p<.03)$ and bone density $(p<67)$, but with an increased inference risk.

Milenkovic S.(2000)on a sample of third grade elementary school children, determines the efficiency of the operation - impact of programmed corrective gymnastics workout and tennis training on transformation of postural, anthropometric characteristics and motor abilities. In postural area scoliosis and flatfoot were analyzed. The obtained values, showed that the program contents of corrective gymnastics sections and tennis school had influenced on transformation of certain manifested variables. This is evident especially in the area of postural disorders. The author points on the justification of organizing and functioning sections of corrective gymnastics and tennis schools.

Milanovic Lj. (2004), in his work starts with a stance that knowing physiognomy of bad posture and the nature of their emergence is extremely important, as a precondition that their prevention and treatment can be approached. The author explains his attitude that the problem in the current conditions can be addressed quite effectively through regular physical education. Author illustrates this thesis by his research conducted on a sample of high-school youth. The conclusion is that, besides a special instruction, solution can be found in the existing conditions, but within the framework of regular physical education classes.

Vasic et al. (2012)conclude that deformity of spinal column in primary school children occurs due to bad posture, sedentary lifestyle, improper seating and reduced physical activity. Physically active children have less pronounced postural disorders of the trunk and the lower extremities (2006). Through intervention of teachers, better postural aspects related to the spine in the correct position of the body, positive influence is gained in later life and back pain can be avoided(2006).

Obesity problem has a negative impact on bone health of mutual composition, causing biochemical changes in the lumbar region of the spinal column and lower limbs (2006). Obese children suffer greater pressure on the central part of their bones that destroys soft tissue (2006).

Dondur S. et al. (2011) compare the differences in research methodology and the results obtained by national and international authors. The results of all the reviewed studies indicate significant changes under the influence of realized corrective programs. Because of this, the main emphasis is on the necessity of prevention and early diagnosis of postural disorders in order to effective corrections. For this reason, authors emphasize the necessity of regular and systematic physical activity.

\section{Practical Applications}

Based on indicators after the end of the experimental program of corrective gymnastics, the obtained results indicate an improvement of the position of the spinal column in thoracic region and in lumbar region, respectively there is significantly fewer respondents with disorders of the spinal column who have been involved in programmed corrective exercise on a regular physical education classes.

It could be concluded that these research results are matching all of the analyzed studies, where statistically significant change under the influence of the applied corrective program was found. For this reason it is necessary to emphasize the necessity of regular and systematic participation of the study population in all aspects of physical activities in order to prevent and later rehabilitate existing postural disorders. For this to take effect, an ongoing cooperation between physical education teacher and students in the various forms of sports, recreational sports, and where necessary also corrective activity application.

Motivation of professors is extremely important, as well as motivation of students. It is necessary to establish plan and program that will have a preventive function, develop a programmed corrective courses, and perform all of that in cooperation with corrective gymnastics experts. Afterwards, 
teachers of physical education would implement planned programs throughout the whole school year in a regular physical education classes, as well as in extra-curricular sport activities.

\section{REFERENCES}

[1] Bogdanovic, Z. (2005), The impact of a programmed corrective gymnastics on postural status of primary school students, $P h D$ Thesis, Nis.

[2] Bogdanovic, Z. (2008), [Spinal deformities in the sagital plane - prevention and correction]. Monografija, State University of Novi Pazar, Novi Pazar.

[3] Bogdanovic, Z. (2010), Korektivna gimnastika [Corrective gymnastics]. Literature, State University of Novi Pazar, Novi Pazar.

[4] Cohen, J.. (1988), Statistical power analysis for the behavioral sciences (2nd ed.). Hillsdale, NJ: Erlbaum. pp. 284-7

[5] Dondur S., Milenkovic S., Veselinovic N., Stojkovic A., Dondur R., Andjelkovic D., Jovanovic S. (2011), A review of research postural disorders of domestic and foreign authors in the period from 2006 to 2009, Facta universitatis - series: Physical education and sport,vol. 9, . 1, pp. 9-24.

[6] Forssberg H, Nashner LM., (1982), Ontogenetic development of postural control in man: adaptation to altered support and visual conditions during stance, The Journal of Neuroscience Copyright 0 Society for Neuroscience, May 1982, Vol. 2, No. 5, pp. 545-552,

[7] Guermazi M, Ghroubi S, Kassis M, Jaziri O, Keskes H, Kessomtini W, Ben Hammouda I, Elleuch MH. (2006), Annales de Readaptation et de Medecine Physique : Revue Scientifique de la Societe Francaise de Reeducation Fonctionnelle de Readaptation et de Medecine Physique, 49(4):172-177.

[8] Gojkovic G.(2009), Effects of physical education on morphological characteristics and postural status of primary school students, Magazine of the Anthropological Society of Serbia,no. 44, pp 171-177, Niksic.

[9] Geldhof, Elisabeth; Cardon, Greet PhD; De Bourdeaudhuij, Ilse PhD; De Clercq, Dirk PhD, (2006), Effects of a Two-School-Year Multifactorial Back Education Program in Elementary Schoolchildren, Spine: 1 August 2006 - Volume 31 - Issue 17 - pp 1965-1973.

[10] Karlin LI, (1986), Injury to the hip and pelvis in the skeletally immature athlete. In The Lower Extremity and Spine in Sports Medicine. Edited by Nicholas JA, Hershman EB. St Louis: Mosby; 1292-1332.

[11] Mannion, Knecht, Balaban, Dvorak, \& Grob. (2004),A new skin-surface device for measuring the curvature and global and segmental ranges of motion of the spine: reliability of measurements and comparison with data reviewed from the literature, European Spine Journal, March 2004, Volume 13, Issue 2, pp 122-136

[12] Madic, D. (2006), Relations of motor and postural status in pre-school children in Vojvodina. In G. Bala (Ed.), Proceedings of "Anthropological status and physical activity of children and youth", vol. 40, (pp. 185-191). Novi Sad: Faculty of Sport and Physical Education.

[13] Milenkovic S. (2000), Determining differences in postural, athropometric and motoric area in third grade students at the beginning and end of school year. Facta universitatis - series: Phisical Education and Sport, 2000, vol 1, no. 7, pp. 39-48, Niš.

[14] Milanovic Lj.(2004), The physiognomy of bad posture and the most common physical deformities in children and school youth - possibilities of preventive treatment and rehabilitation. Journal of Faculty of teacher education, Užice, no. 5, pp. 307-322

[15] Mickle KJ, Steele JR, Munro BJ. (2006), Does excess mass affect plantar pressure in young children? Int J of Pediatr Obes 2006; 1: 183-188.

[16] Obradovic B., Madic D., Milosevic Z., Maksimovic N., Mikalacki M., Kovacev-Zavisic B. (2009), The influence of different kinesiology treatments on body composition and bone mineral content of boys in prepuberty, Medical Review, vol 62, no. 1-2, pp. 23-26. Novi Sad

[17] Protic-Gava B., Krneta Z., Bosković K., Romanov R. (2010), The effects of programmed exercise on the status of the spinal column in eight years old children of Novi Sad. Magazine of the Anthropological Society of Serbia, no. 45, pp. 365-374, Novi Sad. 
[18] Pfeiffer M, Kotz R, Ledl T, Hauser G, Sluga M.(2006), Prevalence of Flat Foot in PreschoolAged Children, Pediatrics Vol. 118 No. 2 August 1, 2006, pp. 634 -639

[19] Purenovic T. (2007), Review of national and international researches in the field of postural disorders - period from 2000 to 2007., Facta universitatis - series: Physical Education and Sport, 2007, vol. 5, no. 2, pp. 139-152.

[20] Post, R.B., Leferink V.J.M. (2004), Spinal mobility: sagittal range of motion measured with the SpinalMouse, a new non-invasive device, Archives of Orthopaedic and Trauma Surgery, April 2004, Volume 124, Issue 3, pp 187-192

[21] Schumway-Cook A, Woollacott MH. (1985), The growth of stability: postural control from a developmental perspective. J Motor Behav 1985; 17: 131-47

[22] Shumway-Cook A, Woollacott MH. (2001), Normal postural control. Motor control: theory and practical applications. Philadelphia, PA: Lippincott Williams, and Wilkins, p. 163-191.

[23] Vasic, B., Marusic, B., Jelenkovic, B., Cukic, N., Ilic, M. (2012), The frequency of the thoracolumbar spinal deformities in children of school age in Zajecar. 2008. Retrieved December 17, 2012, from http://www.tmg.org.rs/tmd27-121130.htm\#121

[24] Wojtys EM, (1987), Section of Orthopaedic Surgery, University of Michigan, Ann Arbor. The Orthopedic Clinics of North America, 18(4):689-708.

[25] Woollacott, M. H.; Inglin, B.; Manchester, D. (1988), Response preparation and posture control in the older adult. Ann. NY Acad. Sci. 525:42-53;

[26] Woollacott, M. H.; Shumway-Cook, A. (1988), Development of posture and gait across the lifespan. Columbia: Univ. of South Carolina Press; Woollacott, M. H. Gait and postural control in the aging adult. In: Bles, W. I.; Brandt, T., eds. Disorders in posture and gait. Amsterdam: Elsevier Science Publishers; 1986:325-335.

[27] Woollacott MH, Shumway-Cook A., Nashner LM, (1986), Aging and posture control: changes in sensory organization and muscular coordination. International Journal of Aging \& Human Development, 23(2):97-114. 